\title{
LA CUENCA DEL \\ PACÍFICO: \\ ASCENSO Y \\ PROYECCIONES
}

Marcos Kaplan*

\section{$\mathbf{U}_{\mathrm{n}}$}

na de las áreas y de las cuestiones cruciales del mundo actual se refieren al desplazamiento del centro del poder económico y político mundial hacia la Cuenca del Pacífico. Es posible y hasta probable que, a comienzos del siglo XXI, la Cuenca del Pacífico sea incuestionablemente el centro económico y político mundial. También, que Japón y China, los países del sudeste asiático, Estados Unidos, la Unión Soviética, se vuelvan los principales actores económicos y políticos del mundo. Desde los años 50, pero sobre todo desde los 70 , el centro del desarrollo y de la civilización se va desplazando desde el Atlántico hacia el Pacífico, y acelerando la dinámica de la historia mundial. A ello correspondería casi seguramente, tarde o temprano, un desplazamiento en términos de poder político y militar.

\section{El trasfondo histórico}

Este viraje histórico se viene preparando durante siglos, sobre todo desde el XIX y principios del XX, y más particularmente desde la Segunda Guerra Mundial. El enfrentamiento entre Estados Unidos y Japón y el cambio que en ese momento se da del centro de gravedad del capitalismo norteamericano hacia la costa occidental de los Estados Unidos, es culminación del proceso que desde el siglo XVI ha ido desplazando el eje del Mediterráneo al Atlántico, y luego hacia el

* Departamento Académico de Estudios Internacionales, ITAM. 
Marcos Kaplan

Pacífico. Este proceso es parte de la formación de la nueva economía mundial y del sistema interestatal con una sucesión de hegemonías y una tendencia a la concentración del poder a escala mundial. ${ }^{q}$

El Pacífico fue virtualmente desconocido por los europeos de la Antigüedad y de la Edad Media, que en casi todos los campos, se arrastran detrás de los principales países de Oriente. Hacia $1500 \mathrm{el}$ despegue económico de Europa se expande e influye sobre todas las sociedades de la tierra; en cuatro siglos logra occidentalizar el mundo.

El Océano Pacífico es reconocido como distinto del Atlántico en 1513; la Cuenca del Pacífico será gradualmente incorporada a la dinámica mundial de los centros occidentales a través de las sucesivas hegemonías de España y Portugal en el siglo XVI, Inglaterra y Holanda durante el XVII, Francia y Rusia en el XVIII, Japón y Estados Unidos en el XIX.

El siglo XVIII es el de las grandes exploraciones, ascenso del comercio intercontinental, crecimiento del imperialismo colonial y luchas comerciales y militares, especialmente entre Francia e Inglaterra, por el control de los territorios coloniales. A fines del siglo las tierras descubiertas por europeos y norteamericanos en el Pacífico y sus costas han sido definitivamente mapeadas.

El siglo XIX es el del ascenso y despliegue de la Revolución Industrial, desde Inglaterra a otros países europeos, Estados Unidos y Japón. Industrialización, ferrocarril y navegación a vapor tienen un papel clave en el poblamiento, desarrollo y sus impactos en Australia, Japón y China. En vísperas del cataclismo de 1914, la división del mundo entre grandes potencias involucra a la Cuenca del Pacífico.

En lo que Eric Hobsbawn llama "La Era del Imperio" (1875-1914),

${ }^{1}$ Sobre la formación de la economía mundial y del sistema político internacional, ver Fernand Braudel, Civilization and Capitalism 15th-18th Century, 3 volúmenes, New York, Harper \& Row Publishers, 1979; Immanuel Wallerstein, The Politics of the World Economy. The States, the Movements and the Civilizations. New York, Cambridge University Press/Editions de la Maison Des Sciences de l'Homme, 1984; George Lichtheim, El Imperialismo, Madrid, Alianza Editorial, 1972. 


\section{LA CUENCA DEL PACÍFICO}

dos regiones principales del mundo fueron, para fines prácticos, completamente divididas: África y el Pacífico. No quedaron Estados independientes en todo el Pacífico, ahora totalmente distribuido entre británicos, franceses, alemanes, holandeses, norteamericanos y -todavía en modesta escala-japoneses. Hacia 1914, excepto Etiopía, la insignificante república afrooccidental de Liberia y la parte de Marruecos que aún resistía la conquista completa, África pertenecía totalmente a los Imperios británico, francés, alemán, belga, portugués y, marginalmente, español. Asia... retenía un área amplia y nominalmente independiente, aunque los más antiguos imperios europeos se extendieron y redondearon sus amplias posesiones. Inglaterra, anexando Birmania a su Imperio de la India y estableciendo o fortaleciendo la zona de influencia en Tibet, Persia y el Golfo Pérsico, Rusia moviéndose más aún hacia Asia Central y (con menos éxito) en la Siberia y la Manchuria del Pacífico, Holanda estableciendo un control más firme sobre las regiones exteriores de Indonesia. Dos imperios virtualmente fueron establecidos, por la conquista francesa de Indochina, iniciada en el período de Napoleón III, y por los japoneses a expensas de China en Corea y Taiwan (1895) y luego más modestamente a expensas de Rusia (1905). ${ }^{2}$

El siglo presencia grandes cambios en la posición relativa de las potencias y de los países en relación a la Cuenca del Pacífico, y el comienzo de una modernización general. Un aspecto central de ello se identifica con la situación y el papel de los Estados Unidos. Ya desde las primeras décadas del siglo XIX,

el mero proceso de la expansión interna era suficiente para mantener la economía de los Estados Unidos en un crecimiento casi ilimitado, aunque colonos, gobiernos, misioneros y comerciantes ya se expandían por tierra hasta el Pacífico o empujaban su tráfico

${ }^{2}$ Eric Hobsbawn, The Age of Empire, 1875-1914, New York, Pantheon Books, 1987 , p. 58. 
Marcos Kaplan

-respaldado por la más dinámica y la segunda flota mercante del mundo- a través del océano, de Zanzibar a Hawai. Ya el Pacífico y el Caribe eran los campos selectos del Imperio Norteamericano. ${ }^{3}$

En regiones como California se van articulando la expansión interna (minas y petróleo) y la externa. Esta última a través de la inversión de capitales, los colonos y el militarismo. A consecuencia de las victorias sobre España en la Guerra de 1898, los Estados Unidos se aseguraron a su vez posiciones de primera importancia en el Caribe (anexión directa de Puerto Rico, indirecta de Cuba, y más tarde el Canal de Panamá), por una parte, y en el Pacífico por la otra (Filipinas, Wake, Hawai).

La "Era del Imperio" presencia también el despliegue de las primeras reacciones hostiles de significación en países conquistados: nacionalismo hindú, despertar árabe, y en China la Guerra de los Boxers y el triunfo de Sun-Yat-Sen con proclamación de la república (1912).

\section{De una Guerra Mundial a la otra}

La Primera Guerra Mundial enfrenta dos bloques: Gran Bretaña, Francia,Rusia, Italia, Japón y los Estados Unidos, por una parte; Alemania, Austria-Hungría, Turquía, por la otra. Alrededor de ambos ejes giran países menores, arrastrados más o menos voluntariamente al conflicto. La "Grande Guerra" sacude al sistema capitalista, lo corroe y vuelve más vulnerable, debilita su prestigio y consenso, marca el fin de un período y el comienzo de otro. La guerra determina la interrupción del desarrollo capitalista mundial, que hasta entonces parecía sin límites: transfiere la riqueza y el poder en su seno, entre naciones y clases; arruina a una parte de la burguesía mundial y refuerza a otra. ${ }^{4}$

${ }^{3}$ Sobre las consecuencias de la Primera Guerra Mundial, ver Jean Baptiste Duroselle, Europa de 1815 a nuestros dias. Vida política y relaciones internacionales, 5a. edición, Editorial Labor, Nueva Clío, 1978; Marcos Kaplan, Formación del Estado Nacional en América Latina, Buenos Aires, Amorrortu Editores, 3a. edición, 1985, Cap. 7.

${ }^{4}$ Para el desarrollo socioeconómico y político y la estrategia diplomática y 
La expansión de Europa, campo de batalla, se debilita y detiene. Los países que combaten, vencedores o vencidos, sufren enormes pérdidas humanas y materiales, se debilitan y empobrecen, y con ellos el capitalismo europeo en su conjunto. ${ }^{5}$

Los beligerantes deben liquidar parte importante de sus activos en el extranjero, especialmente en los Estados Unidos y en América Latina, y obtienen menores ingresos que el resto. Sus exportaciones de capitales no recuperan el nivel de preguerra. El arreglo de las astronómicas deudas de guerra contribuye a la inflación y los problemas cambiarios. La estabilización monetaria internacional se restablece precariamente hasta 1930. Los países desarrollados recurren al proteccionismo para preservar el equilibrio de su balanza de pagos, que traba el libre movimiento internacional de mercancías, capitales y personas. El mercado mundial tiende a retraerse y fraccionarse. La configuración general del comercio internacional se modifica. El intercambio crece más lentamente que la producción mundial.

Entre 1913 y 1926, la participación del comercio mundial entre los continentes se redistribuye. El comercio mundial deja de ser válvula de seguridad para la superproducción capitalista. La recuperación limitada y frágil se cumple además mediante la racionalización, la concentración, el inflacionismo, que tienden a producir más con menos hombres: redistribuyen la renta nacional reducida en beneficio del gran capital y en desmedro de capas medias y proletarias, polarizan la sociedad, crean un estado casi permanente de conflictividad social y política.

Otras circuntancias contribuyen a socavar la posición de Europa como centro del capitalismo mundial. La Europa oriental y sudoriental, hasta 1914 válvula de escape para Gran Bretaña, Francia y Alemania, es

militar de Japón, ver Michel Vié, Le Japon Contemporain, Paris, Presses Universitaires de France, Paris, 1971; Origins of the Modern Japanese State. Selected Writings of E.H. Nomman (ed.John W. Dower), New York, Random House, 1975; Jhon H. Halliday, A Political History of Japanese Capitalism, New York, Random House, 1975; John Whitney Hall, El Imperio Japonés, México-España, Siglo XXI Editores, 1973.

${ }^{5}$ Ramses, Rapport Annuel Mondial sur le Système Economique et les Strategies 86-87, Paris, Atlas-Economica/Institut Français des Relations Internationales, 1987. 
Marcos Kaplan

subdividida en un gran número de unidades nacionales medianas y pequeñas, con escasa viabilidad nacional para el desarrollo interno, e incapaces de seguir funcionando como espacio para la expansión capitalista de los países euroccidentales.

Los cambios limitativos y disruptivos más importantes ocurren fuera de Europa Occidental: el ascenso del Japón y de los Estados Unidos, la Revolución Rusa, la rebelión colonial.

Japón interviene en la Primera Guerra Mundial a favor de quienes resultarán vencedores, sin grandes costos ni riesgos, y ve favorecido su propio desarrollo por el conflicto. Hace oir su voz internacionalmente, se sienta junto a los vencedores en la negociación del Tratado de Versalles. Deja de ser zona de reserva para la expansión europea, y tiende a operar como gran productor y exportador industrial, y como inversor extranjero. Extiende su zona de influencia, con la recepción de antiguas colonias alemanas, la posesión de bases estratégicas en China, la instalación en Corea (1905), en Manchuria (en proceso de industrialización), en las Islas Sakhalin, en el Sudeste asiático. Sin embargo, no pasa de ser todavía una potencia de segunda categoría.

Los Estados Unidos intervienen en la Primera Guerra en 1917, por el peso de sus lazos económicos y financieros con Gran Bretaña y Francia, y como reacción ante la creciente agresividad del imperialismo alemán. Su intervención vuelca la balanza, rompe el equilibrio hacia el triunfo de sus aliados, y con pérdidas insignificantes en hombres y recursos son los principales beneficiarios de la Gran Guerra. Su partipación representa el decisivo punto de flexión, de la era europea a la era de la política mundial.

Los Estados Unidos emergen del conflicto como el más poderoso país industrial, dominante en el mercado internacional, acreedor y principal exportador de capitales, sucesor de Europa en el goce de la hegemonía dentro del sistema capitalista, confiado en su capacidad para el rechazo del viejo orden europeo y mundial y para la imposición de otro nuevo, el acorde con sus intereses e ideologías oficial. A partir de 1918, los Estados Unidos aceleran su expansión en Europa y, sobre todo, en Canadá, América Latina, China y la Cuenca del Pacífico.

La Revolución Rusa amputa al capitalismo un país-contiente, que cesa 


\section{LA CUENCA DEL PACÍFICO}

como mercado, fuente de materias primas, zona de inversiones, para las naciones desarrolladas de Occidente, y se repliega sobre sí mismo en un esfuerzo de desarrollo autónomo y acelerado. El mundo se fractura, estremecido por una guerra ideológica planetaria. Se postula la existencia de una nueva alternativa de desarrollo y de organización de la economía, la sociedad y el sistema político, y se esgrimen las ventajas del Estado fuerte y centralizado, de la planificación autoritaria, del gran espacio continental. Junto con los Estados Unidos, la Unión Soviética flanquea al viejo centro europeo, lo limita y debilita, contribuye a la desaparición de las áreas de libre maniobra y a la congelación de las posiciones de poder en el mundo. El experimento soviético comienza a ejercer casi de inmediato una influencia en la periferia dependiente y colonial de Asia, África y América Latina y, por consiguiente, en la Cuenca del Pacífico.

La retracción del ámbito externo para la recuperación y la nueva expansión de los países capitalistas desarrollados es reforzada por el comienzo de la crisis colonial. Las semillas del cambio y la rebelión han sido sembradas desde antes de 1914. La Gran Guerra moviliza a pueblos coloniales para la lucha, proveedores de soldados, mano de obra, recursos y productos. Los combatientes de color son actores y testigos de la masacre entre los civilizados blancos colonizadores, revelados como vulnerables y capaces de suprema barbarie. Las potencias beligerantes estimulan el nacionalismo en las colonias enemigas, y en ellas y en las propias diseminan como propaganda las ideas de democracia, independencia nacional y autogobierno. Deben además hacer concesiones a los súbditos nativos, cuyo posterior incumplimiento desprestigia y alimenta el descontento. La guera determina interrupciones y cambios de dirección en el comercio, las inversiones internacionales y las actividades productivas y estimula un cierto desarrollo de la industria y la valorización de recursos en los países dependientes y coloniales, contribuyendo al aumento de las capas medias, entre las que comienza a surgir la motivación de la independencia. La Revolución Rusa refuerza el despertar social y nacional; da un ejemplo de revolución posible en un país que desafía a las potencias occidentales y propone nuevas fórmulas para superar la dependencia y el atraso. 
Marcos Kaplan

Bajo el impacto de estos factores, los movimientos nacionalistas toman impulso en las dependencias y colonias desde las postrimerías de la Primera Guerra. Europa conserva en conjunto la esfera colonial de que dispone en 1914, pero su expansión se detiene y comienza a ser cuestionada.

Entre la Primera y la Segunda Guerra Mundial las principales potencias y naciones desarrolladas intentan dar solución al problema no definitivamente resuelto de la hegemonía mundial. Parte crucial de ello es la lucha entre los Estados Unidos y el Japón por la Cuenca del Pacífico. La rivalidad nipo-americana en el Pacífico se perfila claramente desde 1922, en la Conferencia de Washington que limita la flota de guerra japonesa. Japón es al mismo tiempo forzado por las potencias occidentales al abandono de sus posiciones de Chan-tong, China. En 1927, con la llegada al poder del ministerio Tanaka, los grupos militares comienzan a disponer de una influencia creciente. ${ }^{6}$

Con la crisis de 1929, y el consiguiente cierre de numerosos países a los productos nipones, la conquista de nuevos mercados y territorios ricos en recursos agropecuarios y de materias primas se vuelve imperativo vital para Japón. Desde 1931 Japón entra virtualmente en un proceso bélico ininterrumpido hasta 1945, a través de la ocupación militar de Manchuria y la creación del Estado satélite de Manchukuo (1932), y de la guerra con China (julio 1937). Japón abandona la Sociedad de las Naciones en 1933, y se acerca a la Alemania nazi, con el tratado tripartito de septiembre de 1940. Las dificultades con China, sin embargo, impiden que Japón entre en guerra contra la Unión Soviética.

El descontento del gobierno japonés con el pacto germano-soviético de agosto de 1939 dará el pretexto para la neutralidad. El aprovechamiento de la situación desesperada en que se halla Inglaterra después de

\footnotetext{
${ }^{6}$ Ver Paul Kennedy, The Rise and Fall of the Great Powers. Economic Change and Military Conflict from 1500 to 2000, New York, Random House, 1987. Sobre las recomposiciones de fuerzas en la Cuenca del Pacífico ver también: Security, Strategy, and Policy Responses in the Pacific Rim -edited by Young Whan Kihl and Lasrence E. Grinter, Boulder and London, Lynne Rienner Publishers, 1989; Japan and the Pacific Quadrille - The Major Powers in East Asia, Boulder and London, 1987.
} 


\section{LA CUENCA DEL PACÍFICO}

las victorias alemanas de 1940/41 permite al imperialismo japonés lanzarse a los mares del sur y al sudeste asiático. En septiembre de 1940 las fuerzas japonesas obtienen del gobierno de Vichy el derecho de estacionamiento en la Indochina francesa. En septiembre de 1941 el ejército derriba al príncipe Konoye, que busca un arreglo pacífico con Estados Unidos, y da el gobierno al general Tojo. Japón ha intensificado durante 10 años el esfuerzo de sus astilleros navales, y posee en 1941 una formidable flota de guerra, y una considerable flota mercante (tercera del mundo).

La destrucción de gran parte de la flota norteamericana del Pacífico por el ataque a la base de Pearl Harbor, Hawai, el 7 de diciembre de 1941, y el hundimiento tres días después en la Malasia de dos acorazados británicos, aseguran al Japón por mucho tiempo el dominio del mar. Una guerra relámpago de seis meses le da el dominio de un inmenso territorio, rico en alimentos y materias primas (caucho, estaño, petróleo): Con la toma de Hong-Kong, Singapur, y la conquista desde la Indochina francesa de Tailandia y Birmania, el Imperio Británico se derrumba. En el Pacífico, Japón va conquistando Guam y Wake, Borneo y las Celebes, las Molucas, Sumatra, Bali, Timor, Java y las Filipinas, y (con los desembarcos en Nueva Guinea y las Islas Salomón) se coloca en las puertas de Australia y hasta de América (desembarco en las Islas Aleutianas). Estos éxitos extraordinarios, debidos en gran parte a la sorpresa inicial, no compensan por largo tiempo la inferioridad del potencial de guerra japonés frente al de los Estados Unidos ni destruye la moral de éste que, abandonando el aislacionismo se lanza totalmente a la guerra.

Desde fines de la primavera de 1942 se va desplegando la contra-ofensiva de Estados Unidos y sus aliados mediante su supremacía naval y aérea. Desde junio de 1943, el avance norteamericano se va desarrollando de archipiélago en archipiélago. A principios de 1945, los centros industriales del Japón son atacados por las fortalezas volantes B-29. El lanzamiento de las bombas atómicas sobre Hiroshima y Nagasaki fuerza la capitulación del Japón el 2 de septiembre de 1945.

Con la derrota, Japón pierde sus posesiones exteriores. Ello va acompañado por un inmenso trastorno en el Pacífico, y las evidencias de un golpe fatal asestado a la dominación europea en toda la región. La 


\section{Marcos Kaplan}

guerra y la acción japonesa han suscitado en los territorios conquistados un sentimiento de independencia asiática ante el cual los vencedores deben inclinarse. Ocidente en general ha sufrido una irreparable pérdida de prestigio. La descolonización comienza, en India, Indonesia, Filipinas, Indochina. A resultas de la combinación de la guerra internacional con la guerra civil, China triunfa sobre Japón, y la variedad maoísta del comunismo sobre el nacionalismo de Chiang-Kai-Shek. Una dinámica de cambio estremece la Cuenca del Pacífico a partir y a través de la Segunda Guerra Mundial, y su principal consecuencia es el ascenso de ésta a la posición de nuevo eje mundial para el presente y para el siglo XXI.

\section{La dinámica de cambio}

La dinámica que se identifica con el ascenso de la Cuenca del Pacífico a un decisivo papel histórico, fue posibilitada por una serie de cambios políticos y militares y las cristalizaciones a las que dieron lugar. Unos y otras contribuyen a desencadenar desarrollos económicos y tecnológicos que, a su vez, producen impactos en las estructuras sociales, los sistemas políticos, los poderes militares y las posiciones de los Estados e Imperios.

Ante todo, los países de la Cuenca han experimentado dramáticos cambios sociales y políticos. Las potencias coloniales se retiran. Surgen nuevos Estados independientes. Los ocupantes norteamericanos imponen al Japón la reforma constitucional y la desmilitarización. Se aplican reformas agrarias en Corea del Sur, en Japón y en Taiwan. China comunista se aísla y reconcentra para intentar un camino de desarrollo específico.

Los Estados Unidos imponen su hegemonía en una buena parte del Asia y del Pacífico, reemplazando a Gran Bretaña como principal potencia occidental. Hacia los Estados Unidos, que los preservó de la ocupación japonesa, se vuelven en adelante, en lo militar y en lo comercial, los antiguos dominios británicos de Australia y Nueva Zelandia.

La Guerra del Pacífico ha dejado una marca duradera en la conciencia y en la opinión pública de los Estados Unidos, manifiesta sobre todo en 


\section{LA CUENCA DEL PACÍFICO}

la decisión de impedir toda nueva hegemonía de un país asiático en el Pacífico. De alli que hasta fines de la década de 1960 tengan una actitud hostil respecto a China, y se comprometan en la Guerra de Corea y en la de Vietnam. Más tarde, si bien renuncian a todo nuevo compromiso militar en Asia, no dejan de mantener un importante dispositivo de fuerzas marítimas, tropas y armas nucleares en el Pacífico.

A partir de 1945 se abre una fase de hegemonía de los Estados Unidos, en lo militar, lo político, lo económico, lo financiero y lo ideológico. Ya durante la Segunda Guerra Mundial, el centro de gravedad del capitalismo norteamericano se desplaza hacia la costa occidetnal de Norteamérica. El proceso continúa con la enorme expansión económica del Japón en los años de 1960, y su creciente conversión en dínamo económico de la Cuenca del Pacífico. Le sigue el extraordinario despegue industrial de los cuatro Nuevos Países Industriales de Asia: Corea del Sur, Taiwan, Hong-Kong, Singapur, y la más lenta y azarosa industrialización de Tailandia, Malasia, Indonesia y Filipinas.

De este modo, en 1960, el Producto Interno Bruto combinado de los países asiático-pacíficos -con la exclusión de los Estados Unidos- es solamente de un 7.8\% del P.I.B. mundial. Pero hacia 1982, la participación se ha duplicado hasta un 16.4\%. Desde entonces, las tasas de crecimiento del área han excedido las de Europa, Estados Unidos y la Unión Soviética, por márgenes aún mayores. Es probable que hacia el año 2000 se alcance más del $20 \%$ del P.I.B. mundial, igual que Europa o los Estados Unidos. Entre 1973 y 1981, el crecimiento de estos paísestaller junto con el de Japón rompe todos los records históricos, con una tasa anual promedio de $8 \%$ (en el mismo lapso Estados Unidos tiene el 2.7\%, y los países de la Comunidad Económica Europea el 1.9\%).

Durante el mismo período, los Estados Unidos ven modificadas sus relaciones con Asia y el Pacífico, y sus equilibrios económicos internos. El comercio con Asia y el Pacífico es en 1960 sólo de $48 \%$ del comercio con Europa (países miembros de la OECD), pero sube para 1983 a un $122 \%$ del comercio norteamericano-europeo. En 1980, por primera vez, el comercio de Estados Unidos con la Cuenca del Pacífico superó en monto al comercio de los primeros con Europa Occidental. Ya desde los años de 1970 se ve crecer la participación del comercio transpacífico 
Marcos Kaplan

en el comercio mundial, y declinar relativamente la del comercio transatlántico. Estos cambios van acompañados por una redistribución interna de población, empleo, ingreso personal, niveles de vida y servicios, inversiones, recursos humanos, cuyos desplazamientos se refuerzan mutuamente para producir efectos multiplicadores. La redistribución se hace desde el Norte y el Este hacia el Oeste y el Sudoeste, y se traduce en la emergencia de macro-estados como California, Florida y Texas.

Una gigantesca y profunda reorganización de los intercambios mundiales se va produciendo, fundamentalmente en dirección del Pacífico y alrededor del Japón, de sus relaciones económicas con los Estados Unidos y con los nuevos países industrializados en la zona. Así, las participaciones de productos manufacturados en las importaciones norteamericanas se modifican espectacularmente. Entre 1966 y 1983, la parte de Europa cae de 43 a 24\%, la de Canadá, de 23.4 a 19\%, mientras la de Japón aumenta de 20.8 a 25.6\%, y la de los "países-talleres" de Asia se triplica casi de 10.6 a $28 \%$.

Desde hace años, "los Estados Unidos y el Japón han tejido una verdadera red de relaciones industriales, financieras y de investigación que puede hacer pensar en la constitución de un 'bloque' tecnológico coherente". Diferentes factores van confluyendo para impulsar a "esta intensificación de las relaciones nipo-americanas", que "es sin duda uno de los factores que contribuye más a la constitución de una 'Zona Pacífica'..."7

El ascenso de la Cuenca del Pacífico se identifica con el desarrollo de un nuevo eje económico, tecnológico, cultural y político, que articula a Estados Unidos, Japón y los principales países pacíficos. Ello es a la vez uno de los principales factores, una de las partes integrantes y uno de los resultados del proceso general de concentración del poder mundial, de la nueva división mundial del trabajo y del aprovechamiento de la tercera revolución industrial y científico-tecnológica.

${ }^{7}$ Para el actual debate sobre la existencia de una declinación hegemónica de Estados Unidos, ver Paul Kennedy, The Rise and Fall..., cit.; Samuel Huntington, "iThe U.S. Decline or Renewal?", Foreign Affairs, New York, Vol. LXVII, No. $2,1988$. 


\section{LA CUENCA DEL PACÍFICO}

En el contexto de la concentración del poder a escala planetaria el punto de partida contemporáneo de la Cuenca del Pacífico es la imposición de la hegemonía norteamericana desde 1945, hasta los primeros síntomas de su declinación relativa unas tres décadas después. Ello ha expresado fuerzas prexistentes y operantes en los decenios anteriores a 1945, y también el usufructo de un crecimiento sin precedentes de la producción y el comercio mundiales después de 1945, sobre todo el de manufacturas, que por primera vez excede el de productos primarios.

La concentración del poder a escala planetaria y la modificación de su correspondiente jerarquización de países y regiones, se definen por factores, mecanismos e indicadores, referentes a la desigualdad del desarrollo histórico precedente, y a aspectos y niveles económicos, tecnológicos, militares, culturales, sociales y políticos. La dimensión económica debe ubicarse en la perspectiva más amplia de la nueva división mundial del trabajo, su naturaleza e implicaciones. Ella es presupuesto, componente y resultado de la gigantesca mutación del capitalismo, en marcha desde hace décadas. Se manifiesta y avanza desde y a través de la aceleración y profundización de las transformaciones estructurales en los países capitalistas desarrollados; de los avances en la transnacionalización del capital; de la difusión de un modelo específico de crecimiento y modernización neocapitalistas-tardíos y dependientes, o periférico, en especial el redespliegue, la industrialización sustitutiva de importaciones y para la exportación en un número considerable de países del "Tercer Mundo"; el proyecto de restructuración integradora de una parte de la economía mundial y, con ello, de las políticas nacionales, del Estado-Nación y de las relaciones internacionales.

Decisivos cambios estructurales se aceleran y profundizan en los centros capitalistas desarrollados, en Estados Unidos, Japón, Europa Occidental. La concentración y centralización del capital alcanzan dimensiones y grados sin precedentes, vgr. bajo la forma de conglomerados. Los procesos y resultados de la tercera revolución industrial y científico-tecnológica (energía nuclear, informática, autonomación, comunicaciones, telemática, biotecnología) van logrando un uso creciente en el proceso productivo, la sociedad y la cultura, la política y el Estado. 
Marcos Kaplan

La elevación de la productividad y la racionalización de la producción van de la mano con la tendencia a la creación de población redundante o excedente, y con dificultades para la continuidad y avance de la acumulación y la rentabilidad del capital en los centros desarrollados. ${ }^{8}$

Una creciente tendencia a la transnacionalización se encarna y realiza en las empresas multinacionales, convertidas en fenómenos centrales del capitalismo contemporáneo y del sistema mundial.

El surgimiento y progreso impositivo de la nueva división mundial del trabajo se explica por los factores y procesos indicados: surgimiento de un mercado mundial del trabajo en el cual compiten trabajadores de todos los países (capitalistas desarrollados o en desarrollo, y de economías centralmente planificadas). El progreso de la división del trabajo descompone el proceso productivo en operaciones simples y unidades elementales, y permite la sustitución de la mano de obra calificada por la semi o no-calificada, rápida y fácilmente preparable, más barata, controlable y sustituible. Progresan también los medios cada vez más eficientes de transporte y, sobre todo, de comunicación.

De esta manera, las inversiones, los flujos de recursos (financieros, tecnológicos, físicos, humanos), las unidades de producción, se expanden y desplazan, se dispersan y reintegran de diferentes modos. Un vasto movimiento mundial de redespliegue y relevo reordena y redistribuye papeles, funciones y posibilidades de regiones, países, ramas productivas, clases, grupos, instituciones y Estados.

En las economías capitalistas centrales -sobre todo Estados Unidos, Japón, Alemania Federal-se conservan y refuerzan los controles mundiales de los grandes flujos financieros y comerciales, que mantienen y desarrollan las industrias más capital-intensivas, sobre todo en los sectores dinámicos y de avanzada (electrónica, informática, química, nuclear, espacial, genética).

Desde los países capitalistas centrales se exportan a los países subdesarrollados y dependientes más dinámicos, recientemente industrializa-

${ }^{8}$ En cuanto al actual predicamento de la Unión Soviética, ver Moshe Lewin, The Gorbachev Phenomenon - A Historical Interpretation, Berkeley, University of California Press, 1988; Robert G. Kayser, "The U.S.S.R. in Decline", Foreign Affairs, New York, Vol. 67, 1988. 


\section{LA CUENCA DEL PACÍFICO}

dos o en camino de industrialización acelerada, con bajos costos salariales y sociales y considerables mercados (actuales y potenciales), las industrias trabajo-intensivas y polucionantes, y algunas industrias básicas (textiles, automóvil, química, electrónica, astilleros, siderurgia, ciertos bienes de capital).

$\mathrm{Al}$ mercado mundial del trabajo corresponde así un mercado mundial de emplazamientos industriales; en ambos, los países desarrollados de economía de mercado, los países en desarrollo, e incluso algunos países de economía centralmente planificada, compiten para atraer, mantener o ampliar la producción industrial, mediante estímulos varios. (Estos son básicamente, la dotación en condiciones excepcionalmente favorables de capital, créditos, exenciones fiscales, tierras, instalaciones industriales, energía, transporte, agua y electricidad; fuerza de trabajo barata y bajo control; condiciones políticas de orden contra perturbaciones sindicales y de hostilidad a la inversión extranjera.)

Este gigantesco movimiento de redespliegue, deslocalización y relevo, se da por impulso, bajo el control y en beneficio de las empresas transnacionales y sus Estados. Las nuevas implantaciones industriales se expanden como inversiones privadas, bajo la forma de sociedades financieras, comerciales, industriales y de ingeniería, y con la contribución de la gran banca internacional.

El capitalismo mundial responde así a las exigencias de industrialización del "Tercer Mundo", -sobre todo los países de éste que evidencian deseo y capacidad de incorporación al proceso- con nuevas especializaciones deformantes y subordinantes, y convirtiéndolos en relevos para la restructuración de la economía mundial bajo la hegemonía y en la órbita de algunos de los países centrales. Al mismo tiempo y en el mismo proceso, el capitalismo mundial valoriza sus capitales de origen, se reproduce y desarrolla al menor costo y con el mayor beneficio posibles.

Los países sometidos a esta especialización restructurante asumen la provisión de productos primarios e industriales, a bajos costos y precios, y son inducidos a la importación de bienes de capital, equipos y tecnología y a financiamientos externos, o a confiar los proyectos a inversiones extranjeras. Las empreseas transnacionales y sus Estados presentan a los países en desarrollo estrategias de crecimiento y modernziación y 
Marcos Kaplan

ofertas globales que interrelacionan equipos, tecnología, financiamiento, inversiones compartidas - con frecuencia todo integrado en un paquete único. Este proceso permite a veces rápidos resultados en ciertos indicadores de crecimiento cuantitativo, pero también aumenta las necesidades de importación y de divisas de los países en desarrollo, de exportaciones especializadas y de nuevos financiamientos. Ello realimenta y refuerza la tendencia a las nuevas importaciones de quipos y tecnologías, de nuevas inversiones directas y de mayor endeudamiento externo. La misma dinámica contribuye a reducir o destruir las capacidades de innovación tecnológica y de investigación científica, de producción de bienes de capital y equipamiento de los países en desarrollo.

Dentro de este proceso general adquieren características especiales los Nuevos Países Industriales (Taiwan, Hong-Kong, Corea del Norte, Singapur), que logran avances notables bajo un común patrón de industrialización. Éste abarca: la planificación centralizada por una tecnoburocracia militar/civil; el control autoritario del mercado del trabajo y la explotación sistemática de la mano de obra barata; la inyección de capital extranjero; la creciente especialización que los aleja del énfasis en la producción de bienes de consumo, hacia la industria básica y la alta tecnología (semiconductores, computadores, telecomunicaciones).

De manera más general, el crecimiento económico en la Cuenca del Pacífico se ha beneficiado con la concurrencia de una constelación de factores interrelacionados. El ascenso espectacular en la productividad industrial se ha dado en sociedades orientadas a la exportación. Ello a su vez lleva al fuerte movimiento hacia los servicios de comercio exterior, marítimos, financieros, hacia nuevas tecnologías y manufacturas trabajointensivas más baratas. El aumento de la producción agropecuaria ha supeado el crecimiento total de la población. Cada éxito ha interactuado con los otros, para producir una tasa de expansión que eclipsa la de los poderes occidentales tradicionales, y la de los países del COMECON. 


\section{LA CUENCA DEL PACÍFICO}

\section{Balance y perspectivas}

Este proceso no ha podido menos que producir cambios trascendentales en los equilibrios económicos, políticos y estratégicos del mundo. Los principales países de la Cuenca y ésta en su conjunto logran niveles históricos de crecimiento; aumentan su participación en el producto bruto mundial, en el comercio internacional, en las cifras globales de producción manufacturera, de innovación tecnológica. Los centros industriales y tecnológicos de la sociedad mundial se desplazan hacia la llamada Comunidad telectrónica del Pacífico Norte. La Tercera Revolución Industrial y Tecnológica es la primera que ya no se origina en la costa atlántica de Europa. En Tokio, Hong-Kong, Singapur, se constituyen los nuevos centros financieros de interés mundial, que van desplazando a los tradicionales de Amsterdam, Londres y New York. Importantes centros de operaciones antes radicados en New York, trabajan ahora en California.

Todo ello se identifica con cambios en la división mundial del trabajo, en los grandes patrones y flujos de producción y comercio, y en las relaciones internacionales. Se da una creciente interdependencia económica entre los países asiáticos del Pacífico, en un contexto más global de desarrollo desigual con una mayor concentración del crecimiento en la parte septentrional y occidental de la Cuenca, y una desaceleración en el Este, relativa en Estados Unidos, absoluta en América Latina.

La Cuenca del Pacífico forma parte del proceso de continuos cambios en el sistema internacional, en términos de riqueza, poder, fuerza económica, capacidad militar, y en la situación relativa de las grandes potencias, de los países desarrollados y de los pertenecientes al "Tercer Mundo". El dinamismo económico modifica el ambiente político mundial, crea nuevas correlaciones de fuerzas, produce cambios políticos y militares y se entrelaza con ellos. Es previsible el ascenso de cinco constelaciones de poder económico-político mundial, la pentarquía integrada por Estados Unidos, Japón, China, Unión Soviética y la Comunidad Económica Europea. China y Japón están ascendiendo como potencias regionales. La Comunidad Económica tiende a reforzarse en la estructura del poder mundial y puede llegar a ser el mayor bloque 
Marcos Kaplan

económico. Es compleja y ambigua la presencia de la Unión Soviética, que combina la estabilización con la tendencia a la lenta baja. Es relativamente rápida la baja de Estados Unidos, aunque conserve una gran fuerza económica, militar y política. A esta constelación debe agregarse la presencia relativamente menor pero significativa de los principales Nuevos Países Industriales.

En una dialéctica de la hegemonía, la interdependencia y la multipolaridad, las nuevas constelaciones de poder y las nuevas correlaciones de fuerza coexisten con una situación y proceso en que las superpotencias no se replantean hasta el momento los criterios políticos y militares aplicables a la Cuenca del Pacífico y continúan aferrados a los esquemas de la bipolaridad. Al mismo tiempo se constituye e impone una estratificación productiva-tecnológica, que separa a las potencias y países industrializados de los países en desarrollo. La estratificación coexiste y se entrelaza con las competencias de intereses y poderes, y con los cuestionamientos y replanteos de las tendencias multipolarizantes. Los polos de poder y las constelaciones de intereses de los países emergentes no aceptan la supeditación a los intereses globales de las superpotencias.

Así, los Estados Unidos mantienen su predominio en un contexto de estratificación/multipolaridad. Se enfrentan, sin embargo, a una relación compleja y contradictoria con Japón. Se trata de una relación de interdependencia más o menos asimétrica y de alta complejidad, con entrelazamiento, coincidencia y oposición de intereses, que ha sido motor del proceso de la Cuenca del Pacífico, con la incorporación creciente de otros países. Las corrientes comerciales, financieras y tecnológicas de Estados Unidos y Japón, y la estabilización política de la Cuenca del Pacífico, han ido produciendo desarrollos complementarios, interdependencias, cambios productivos, tecnológicos y una división regional del trabajo. Ello coexiste y se interrelaciona con la competencia intercapitalista entre Estados Unidos, Japón y los Nuevos Países Industriales. A ello se agregó, hasta hace poco tiempo, la rivalidad Oeste-Este; la competencia intersocialista entre la Unión Soviética, China, Vietnam, Campuchea. Mercados y espacios político-militares son disputados también por todos aquellos actores, además de Australia, Surcorea, Singapur, Taiwan y Hong-Kong, con lo que se van esbozando bloques 


\section{LA CUENCA DEL PACÍFICO}

sub-regionales, con variable peso político-colectivo. En cuanto al predicamento y tendencias de los principales actores en el escenario histórico de la Cuenca del Pacífico, deben anotarse algunas referencias.

Los intereses económicos, políticos y militares de los Estados Unidos en la Cuenca del Pacífico, sin carecer de especificidad, se subsumen en la globalidad de intereses y el liderazgo general de aquéllos. La hegemonía impuesta desde 1945 por las altas participaciones relativas en los indicadores fundamentales del poder mundial, ha ido sufriendo una progresiva erosión en las últimas décadas, enmascarada al principio por la impresionante expansión de la posición hegemónica y competitiva en las décadas de 1950 y 1960 . La erosión ha expresado la convergencia de fenómenos y procesos como los vinculados con la recuperación de Europa Occidental y Japón, la emergencia de nuevos centros de industrialización, el despliegue de tendencias críticas seculares de la economía norteamericana. Ello no ha podido menos que plantear graves problemas políticos y estratégicos a dirigentes y grupos dominantes de los Estados Unidos.

Así, por una parte, frente a la situación y tendencias de la multipolaridad, Estados Unidos se inclina a respaldar los polos de poder que apoyen su control y mantengan o refuercen el equilibrio en la Cuenca. Ello implica el fortalecimiento de las capacidades y las posiciones políticas y militares de los Estados Unidos y de sus aliados en la Cuenca, según criterios obsoletos y discordantes respecto a los de los países integrantes de aquélla; especialmente la consolidación del sistema de seguridad de la Cuenca frente a la Unión Soviética y a la China Popular. Estados Unidos ha visto amenazada su supremacía en la Cuenca por la presencia de la Unión Soviética, por el debilitamiento de su pacto militar con Australia y Nueva Zelandia (ANZUS) -vgr. negativa de Nueva Zelandia a los Estados Unidos al derecho de uso de su territorio como base de operaciones militares y política antinuclear.

Por otra parte, la supremacía de los Estados Unidos se ve minada por la contradicción entre el apoyo que quiere dar a los países amigos de la Cuenca y la creciente competencia que algunos de éstos le hacen, en especial Japón y los Nuevos Países Industriales. Los Estados Unidos muestran hostilidad a la penetración de sus mercados, con el proteccio- 
Marcos Kaplan

nismo, restricciones diversas y con el pedido de medidas para reducir desequilibrios; por ejemplo, respecto al Japón, demandas sobre la revaluación del yen, las exportaciones norteamericanas, leyes impositivas, transferencias de dinero del ahorro al consumo, reparto de un mercado menor entre Japón y otros países rivales del Pacífico, mayor participación en los gastos de la defensa de la Cuenca.

De manera general, la posición de los Estados Unidos en la Cuenca se ve afectada por ciertos procesos críticos de su economía, declinación de la productividad industrial y agrícola y desequilibrios financieros, en el marco de sus normas compromisos mundiales y de "sobre-extensión imperial". La reducción de la capacidad económica relativa y la amplia gama de desafíos externos a la hegemonía obligan a dedicar más recursos a lo militar y menos a la inversión productiva, al crecimiento y a los gastos sociales, lo que reduciría la capacidad para soportar el peso de la defensa. De todos modos, si la hegemonía de los Estados Unidos declina, no por ello desaparece, y conserva en un mundo multipolar una alta significación, por la fuerza propia y por la que deriva de su capacidad de articular e instrumentar alianzas.

El Japón ha experimentado un crecimiento y modernización espectaulares, demostrando una alta capacidad de superación, digna de emulación. Un conjunto de factores favorables ha permitido la emergencia del llamado "milagro japonés", que se refleja en los indicadores y cifras de crecimiento del Producto Interno Bruto; del predominio mundial en el número de industrias que van de la baja a la alta tecnología; de los excedentes comerciales; de la combinación entre el gigantismo industrial y el financiero; de la conversión de principal acreedor neto en gran inversor; del enriquecimiento continuo en el P.I.B. per cápita y en el nivel de vida.

Japón ha aprovechado las ventajas de un desarrollo sin responsabilidades políticas y militares, pero ha ido entrando en una fase que suscita peligros y temores de diverso tipo. En la madurez el crecimiento se hace más lento y aumentan las presiones de aliados y rivales: de los Estados Unidos y Europa Occidental para que reduzcan su agresiva y exitosa competencia; de los países que quieren emularlo y superarlo, como los Nuevos Países Industriales y China. Esta situación induce al Japón a la 
huida hacia adelante, hacia los sectores más prometedores y rentables para el siglo XXI, los de alta tecnología y manufacturas de mayor valor agregado. La acumulación de enormes excedentes financieros y las necesidades de materias primas, energéticos y mercados impulsan al desarrollo de las inversiones externas, al establecimiento y reproducción de sus industrias en otros países, al refuerzo de la cooperación e interdependencia con países de la Cuenca Pacífica.

Este complejo predicamento no deja de producir múltiples incidencias en la política internacional del Japón. Ante todo, dificulta el diseño y realización de una política exterior coherente. Japón ha intentado sobre todo aplicar la llamada "Diplomacia pacífica omnidireccional", que significa "ser todas las cosas para todos los hombres", dar prioridad a la solución pacífica de los problemas internacionales, evitar situaciones de encrucijadas y peligros de fuegos cruzados, tratar de estar bien con todos sin dejar de proseguir su carrera al enriquecimiento. Ello ha planteado, entre otros, el dilema que obligaría a optar entre la productividad y la prosperidad, o la fuerza militar y los gastos de defensa. Los Estados Unidos presionan al Japón para que adquiera un mayor compromiso en defensa, seguridad y rearme. Las objeciones de diferentes sectores del Japón son en parte domésticas: bien fundados temores al resurgimiento del militarismo y el imperialismo, a las posibles pérdidas, a la destrucción nuclear, a un freno al crecimiento y competividad, a la baja del nivel de vida; y en parte externas: desconfianza de parte de la Unión Soviética, China Popular y los antiguos países ocupados. Por otra parte, si el Japón insiste en extender el modelo de industrialización que le es propio a toda la Cuenca del Pacífico y convertir a ésta en zona privilegiada de desarrollo bajo su influencia y en su beneficio, sin inducir graves enfrentamientos políticos, y si al mismo tiempo aumenta su fuerza y presencia militares y participa en una zona desnuclearizada, como la propiciada por Australia y Nueva Zelandia, la hegemonía política y militar de los Estados Unidos se vería seriamente afectada.

Los Nuevos Países Industriales llamados "Los cuatro dragones del Pacífico" se han desarrollado a partir de los apoyos, ingerencias y controles de los Estados Unidos y el Japón, pero cada vez más lo hacen con sus dinámicas y finalidades propias. Compiten con los Estados Unidos y 
Marcos Kaplan

el Japón sin dejar de depender de su prosperidad y buena voluntad, y al mismo tiempo ven pisados sus talones por nuevos candidatos al estatus de que disfrutan.

Como los Nuevos Países Industriales asiáticos, los de la ANSEA (Asociación de Naciones del Sudeste Asiático) se han ido desplazando desde una organización pronorteamericana a una neutralista, a una mayor conciencia de sus intereses regionales y a un creciente recelo de las pretensiones hegemónicas de Estados Unidos y Japón, que podrían amenazar su propia dinámica de crecimiento, cooperación económica y sus principios de no alineamiento, e involucrarlas en el armamentismo y la nuclearización. La perspectiva de la integración regional les permitiría no dejarse absorber en un esquema mayor bajo hegemonía de una gran potencia. A la inversa, para los Estados Unidos la ANSEA podría contrapesar a los países indochinos con inclinación favorable a la U.R.S.S., como Vietnam, Laos y Campuchea.

Los países desarrollados de Oceanía, Australia y Nueva Zelandia tienen evidente interés económico en una integración de la Cuenca del Pacífico, que les permitirá superar la estrechez de sus mercados y les otorgue más espacios para un comercio global. Tienen además un interés político en el relajamiento de las tensiones, la paz y la estabilidad, también condiciones para la expansión económica. De ahí su interés en la desnuclearización del Pacífico Sur y en la creación y avance del Foro del Pacífico Sur.

China parece involucrada en un proceso de modernización, crecimiento y apertura al mundo exterior sin aceptación de hegemonías ni dependencias. Con la experiencia de las movilizaciones y vicisitudes pasadas, la conciencia de sus fracasos pero también de sus logros y del tremendo potencial (económico, político, militar), la participación de China en la Cuenca del Pacífico produce actualmente grandes expectativas. Su inclusión sería la de una potencia emergente, enorme mercado, eventual campo de inversiones foráneas, contrapeso a las hegemonías y refuerzo a la multipolaridad en la región, con un consecuente reordenamiento del esquema estratégico. China por su parte incluye entre sus expectativas las de satisfacción de las necesidades de capital, tecnología, comercio y 


\section{LA CUENCA DEL PACÍFICO}

el deseo de relaciones pacíficas en la independencia, el antiintervencionismo y la equidistancia respecto a las potencias.

La Unión Soviética tiende a moverse casi inevitablemente hacia la Cuenca del Pacífico, a la cual pertenece por razones geográficas y por la gravitación hacia y desde los grandes vecinos, a los cuales amenaza, pero por los cuales también se siente amenazada. La URSS viene sufriendo cada vez más visiblemente una multidimensional declinación, ya oficialmente reconocida, en lo demográfico, económico, productivo, tecnológico y militar. La reducción de su estatus económico relativo tiene implicaciones a largo plazo en cuanto a su participación en la estructura del poder mundial. Ni condenada al colapso, ni apta para una pretensión de omnipotencia, la URSS encara opciones difíciles, parte de la problemática de la Perestroika, que incluyen a la Cuenca del Pacífico.

La URSS está justificadamente preocupada por su flanco asiático. Su expansión secular en Asia se ha detenido, con la presencia de China, India, Japón, los más pequeños pero agresivos Estados asiáticos en pleno avance industrial, el fundamentalismo musulmán, los conflictivos espacios de Corea, Vietnam y Afganistán. La vasta periferia es siempre insegura y peligro de alta vulnerabilidad en caso de guerra. En su estrategia hacia la Cuenca del Pacífico, la Unión Soviética pone énfasis en lo económico, presenta un bajo perfil militar, se preocupa por participar en los nuevos mercados, las formas emergentes de cooperación económica y las posibilidades de desarrollo futuro. La Unión Soviética sabe que provoca la desconfianza y el temor de las otras potencias y de China, pero también conoce la existencia de un temor de los países de la Cuenca en cuanto a la confrontación de las superpotencias. La Unión Soviética favorece las demandas de los países pequeños y medianos, la desnuclearización, el acercamiento y la cooperación económicas. Todo ello se ha acentuado con los recientes cambios provocados por el proyecto reformista de Mijaíl Gorbachov. La URSS manifiesta su deseo de ingresar al Banco Asiático de Desarrollo y a la Conferencia de Cooperación Económica del Pacífico. Ha firmado convenios comerciales con países de Indochina. Se interesa vivamente por las perspectivas prometedoras que las economías de la Cuenca ofrecen al sector externo de la propia. Gorbachov convocó en su discurso de Vladivostok (junio 1986) 
Marcos Kaplan

a una Conferencia Internacional de Seguridad en el Pacífico, y visita oficialmente los países de la región para promoverla.

La Cuenca del Pacífico se va constituyendo como espacio de cooperación, a partir y a través de las Conferencias de Comercio y Desarrollo del Pacífico que surgen desde el decenio de 1960; el Consejo Económico de la Cuenca del Pacífico (1967); la Conferencia de Cooperación Económica del Pacífico y su serie de multilaterales de consulta, desde el surgimiento en 1980, hasta la última en Japón, 1988. El proceso de integración está aún en una etapa embrionaria, sin definición previsible por el momento en cuanto mero espacio de diálogo y consulta multilateral, u organismo de integración económica (zona de libre comercio, unión aduanera, mercado común), condicionada y restringida en sus posibilidades y definiciones por la heterogeneidad de los intereses económicos y políticos de los países componentes.

La Cuenca del Pacífico no deja sin embargo de irse constituyendo gradualmente, en la interdependencia económica asimétrica y la multipolaridad político-militar jerarquizada, como parte de un proceso de extensión de la economía mundial y de transformación del sistema interestatal, de continuidad de los cambios en los equilibrios de poderes. Para México y América Latina, la Cuenca representa una innegable gama de vastas posibilidades, que no puede ignorarse, menospreciar ni desaprovechar, pero que tampoco debe ser idealizada. No se puede esperar buena voluntad ni predisposición filantrópica de las potencias de la Cuenca ni de los varios pelotones de Nuevos Países Industriales. Tampoco puede esperarse un aprovechamiento oportuno y eficaz de las oportunidades que podría abrir la Cuenca del Pacífico, en base a la continuidad del camino tradicional de crecimiento y modernización que América Latina emprendió en las últimas décadas. Este camino no asegura las capacidades para integrarse en la Nueva División Mundial del trabajo ni en la Cuenca del Pacífico, y competir en una y otra con grandes potencias, países altamente desarrollados y nuevos países industriales. Aquí como en todos los aspectos de la problemática latinoamericana y del "Tercer Mundo", la primacía está en un nuevo camino/estilo de desarrollo integral y en el avance hacia formas más avanzadas de integración regional. Sólo ello puede quizá garantizar las condiciones 


\section{LA CUENCA DEL PACÍFICO}

de incorporación a un proyecto de desarrollo histórico a largo plazo de la Cuenca del Pacífico, que asegure la interdependencia con autonomía y la participación real y creciente en los beneficios del nuevo espacio/eje mundial. 